
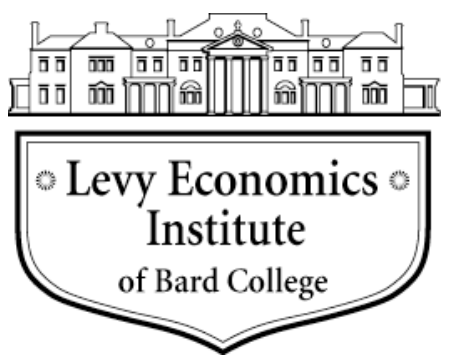

Working Paper No. 718

\title{
Aggregate Production Functions and the Accounting Identity Critique: Further Reflections on Temple's Criticisms and Misunderstandings
}

\author{
by \\ Jesus Felipe \\ Levy Economics Institute of Bard College \\ Asian Development Bank \\ John McCombie* \\ Cambridge Centre for Economic and Public Policy, University of Cambridge
}

May 2012 *E-mails: jfelipe@adb.org; jslm2@cam.ac.uk. The views in this paper solely represent those of the authors, and
not those of the Asian Development Bank, its member countries, or those of its executive directors.

The Levy Economics Institute Working Paper Collection presents research in progress by Levy Institute scholars and conference participants. The purpose of the series is to disseminate ideas to and elicit comments from academics and professionals.

Levy Economics Institute of Bard College, founded in 1986, is a nonprofit, nonpartisan, independently funded research organization devoted to public service. Through scholarship and economic research it generates viable, effective public policy responses to important economic problems that profoundly affect the quality of life in the United States and abroad.

Levy Economics Institute

$$
\text { P.O. Box } 5000
$$

Annandale-on-Hudson, NY 12504-5000

http://www.levyinstitute.org

Copyright (C) Levy Economics Institute 2012 All rights reserved

ISSN 1547-366X 


\begin{abstract}
In a reply to Felipe and McCombie (2010a), Temple (2010) has largely ignored the main arguments that underlie the accounting identity critique of the estimation of production functions using value data. This criticism suggests that estimates of the parameters of aggregate production functions cannot be regarded as reflecting the underlying technology of the industry. While Temple concedes some points, he erroneously believes that the critique holds only under some ad hoc assumptions. As a consequence, he argues that the critique works only "part-time." This rejoinder discusses Temple's arguments and demonstrates that the critique works full-time.
\end{abstract}

Keywords: Accounting Identity; Aggregate Production Function; Aggregation Problems; Value-added Identity; Value Data

JEL Classifications: C43, O11, O16, O47, O53 


\section{INTRODUCTION}

In a number of papers, Felipe and McCombie have pursued the argument that because of an underlying accounting identity (where the value of output is definitionally equal to the wage bill plus the operating surplus), the coefficients obtained in econometric estimations of production functions using value data cannot be interpreted as the true technological parameters. This stands in contrast to the use of physical data, e.g., engineering production functions, which can, under certain circumstances, tell us something about the underlying technology. ${ }^{1}$ However, because of data limitations, such studies are few and far between. We define an aggregate production function as one that is estimated using constant price value data. The reason is that the heterogeneity of the myriad of outputs and capital stocks (broadly defined) requires that their summation uses their prices. And so the problem of the identity applies to industries at, say, the four-digit SIC, as much as it does to the whole economy.

Temple (2006) raised a number of objections to our arguments, none of which is compelling (Felipe and McCombie, 2010a). In a rejoinder, Temple (2010) concludes that we make substantially more of the criticism of production functions estimated using value data (at any level of aggregation) than it deserves. Hence, he labels it "the part-time tyranny of the identity." However, he largely repeats the objections of his 2006 paper and generally ignores our counter-arguments. While he concedes that there are some areas of agreement and that the argument deserves to be better known, he contends that we have gone too far and exaggerated the scope and implications of the argument. To do so, he reviews some of our work and disputes a number of our conclusions.

In this rejoinder, we clarify a number of issues that Temple (2010) raises, even though we have already dealt with some of them in our earlier reply (Felipe and McCombie, 2010a). We stand by the full extent of the implication of our argument, namely, that the use of value data (as opposed to physical quantities) in the estimation of any specification of an aggregate production function, whether or not it is a Cobb-Douglas, precludes the researcher from interpreting the

\footnotetext{
${ }^{1}$ There is no accounting identity problem if output is the number of identical widgets, and inputs are the numbers of identical employees and the number of Joan Robinson's "leets." Likewise, an agricultural production function relating, say, the yield per acre of bushels of wheat to the degree of soil fertility, the amount of fertilizer per acre, and the amount of sunshine and rain does not encounter this problem.
} 
regression results as the technological parameters (e.g., the factor output elasticities or the elasticity of substitution). However, Temple considers that the critique only relates to the CobbDouglas relationship. We also argue that it is true for any level of aggregation using value data. The aggregate production function is, in fact, unlikely to exist, not least because of serious aggregation problems and variations in $x$-efficiency, etc. The only certainty is that the regression results and the values of the estimated parameters are determined by the accounting identity. The tyranny of the identity works "full time."

Temple, nevertheless, agrees with us on two points. The first one is that the aggregation problem should receive more attention in the literature than it does, although he argues that there are other approaches that are not so reliant on aggregation, e.g., the use of multi-sector models, reduced-form regressions, and methods inferring productivity levels from bilateral trade data (Temple 2010,686). We do not deal with this view here, but concern ourselves solely with the problems posed by the accounting identity for the aggregate production function. Both the Cambridge capital controversies and the more general aggregation literature suggest that even under constant returns, the conditions for aggregation are so very stringent as to make the existence of aggregate production functions in real economies a non-event. This is true not only for the existence of a capital stock, but also for such constructs as aggregate labor or even aggregate output. ... One cannot escape the force of these results by arguing that aggregate production functions are only approximations. (Fisher 2005, 490)

Indeed, Temple $(2005,438)$ himself gives the simple example that two Cobb-Douglas production functions with different exponents cannot be aggregated to give a single Cobb-Douglas production function. ${ }^{2}$ Surprisingly, later in his comment, he declares himself "agnostic" on this issue (Temple 2010, 689), though no compelling reasons are given for this. It is not clear why aggregation problems disappear and a true production function can be estimated if "we have no prior reason to believe that output and inputs are badly measured" (Ibid.), especially when it is agreed that the accounting identity critique has nothing to do with measurement errors.

\footnotetext{
${ }^{2}$ Nevertheless, ironically, this does not stop Temple (2005) from assuming that the production functions of agriculture and non-agriculture are each represented by an aggregate Cobb-Douglas, and that factors are paid their aggregate marginal products, as if aggregation problems did not matter for these sectors.
} 
The second area where there is agreement is that an applied researcher may appear to obtain meaningful results from estimating a production relationship, even when the researcher is making assumptions that do not hold in the data.

One important instance arises when factors are not paid their marginal products. In that case, although researchers often interpret their results as if the estimated parameters can be used to derive output elasticities, the identity suggests that the estimates may be more closely related to the factor shares. (Temple 2010, 686; emphasis added)

This would seem to go a long way to conceding our position and poses difficulties for understanding the rationale for his criticisms. We would indeed agree with this statement, except that the identity shows, not suggests, that the estimated coefficients will take values that are equal to the factor shares, even when no well-defined aggregate production function exists. ${ }^{3}$ An implication of Temple's statement cited above is that given that the researcher has only access to constant price value data; it can never be known whether or not the researcher is correctly estimating the parameters of a production function, or, indeed, whether or not the latter exists. This is precisely our critique.

Yet, at times in his reply, Temple (2010) takes the opposite view, and argues erroneously that if factor shares vary to an unspecified extent and the researcher can correctly specify "total factor productivity," all will be well. The aggregate production function can then be estimated and the values of the coefficients will correctly reflect the aggregate technological parameters of the economy, albeit with the necessity of finding the most appropriate statistical estimating technique.

In the rest of this article, we briefly point out the problems with Temple's (2010) arguments. Broadly speaking, there are two issues that we wish to emphasise. First, Temple erroneously continues to imply that the critique only holds if certain ad hoc, or what he terms auxiliary, assumptions are made; typically the "stylized facts" that factor shares are constant and the weighted growth of the wage rate and the rate of profit are constant. To this he incorrectly adds, in the case of our critique of Mankiw et al.'s (1992) growth model that we have, of

\footnotetext{
${ }^{3}$ Where this does not prove to be the case, it is because the mathematical transformation of the identity to give a specific functional form (i.e., what the neoclassical economist calls the aggregate production function) does not accurately mirror the identity. In other words, this is when the statistical fit of the transformation is less than perfect. We elaborate on the reasons for this below.
} 
necessity, to assume also a constant capital-output ratio for the criticism to hold. At times, as we noted above, he seems to assume that the critique only applies to the case of the Cobb-Douglas and so, presumably, once there is some variability in factor shares, he implies that we can actually be confident we are estimating a "true" aggregate production function. He nowhere answers the question posed by Felipe and McCombie (2010a) as to how much variability in factor shares is required to suddenly remove the problems posed by the accounting identity and aggregation problems.

Secondly, we show below that his argument at times reduces to petitio principii, or circular reasoning. Temple sometimes assumes that the aggregate production function exists, and uses this assumption to supposedly counter the argument that the relationship between output and inputs in value terms does not necessarily reflect a technological production relationship.

\section{RESPONSES TO TEMPLE'S ARGUMENTS}

In what follows, we discuss some specific problems in Temple's (2010) reply.

\section{Economic Rents and the Actual and Virtual Accounting Identities}

Temple implies that for the critique to hold (his discussion is in the context of the Solow residual), rents need to be excluded from the accounting identity (Temple 2010, 688). However, the accounting identity simply shows how value added is measured. This is given by the identity $V \equiv W+\Pi$, where $W$ is the wage bill and $\Pi$ is the operating surplus. The latter includes all types of profits. All we do is to split the wage bill into the product of the average wage rate $(w)$ multiplied by employment $(L)$; and the surplus into the product of the average rate of return $(r)$ times the value of the stock of capital $(J)$. This implies that $V \equiv W+\Pi=w L+r J$. This requires no economic assumptions whatsoever and holds true by definition. This identity may be written in growth form as $\hat{V} \equiv a_{t} \hat{w}_{t}+\left(1-a_{t}\right) \hat{r}+a_{t} \hat{L}_{t}+\left(1-a_{t}\right) \hat{J}_{t}$ where $a_{t}$ is the labor share and $\left(1-a_{t}\right)$ is the capital share and these may vary over time.

Unfortunately, Temple seems to confuse the "actual" accounting identity with what we have termed elsewhere the neoclassical "virtual" identity (Felipe and McCombie 2007), based upon the assumption of perfectly competitive markets and optimisation. Consequently the latter may, or may not, hold in reality. This is usually derived at the microeconomic level by applying 
Euler's theorem to the micro-production function, together with the assumption that the marginal theory of factor pricing holds, i.e., $p Y=p F(L, K)=p(\partial Y / \partial L) L+p(\partial Y / \partial K) K=w L+\rho K$ where $Y$ is output and $K$ is capital, both measured in physical terms, and $\rho$ is the rental price of capital. $p$ is the price of a unit of output. This chain of reasoning is then applied seamlessly in neoclassical production theory to the macroeconomic level, regardless of the fact that output is value added $(V)$ - not units of physical output - and capital is not the stock of homogeneous structures and equipment, but the constant price value of the stock of capital $(J) .{ }^{4}$ If an estimate of the competitive rate of profit is used in the accounting identity, then the implied economic rents would have to be deducted from value added and the argument follows through exactly (Ibid.).

\section{The Accounting Identity Critique Does Not Hold Only When Factor Shares Are}

\section{Constant}

Temple argues to the contrary that the identity argument only holds with constant factor shares and a constant weighted growth of the wage rate and the rate of profit, which he claims we have to introduce as arbitrary or ad hoc assumptions. This is most clearly seen in the following:

All of their [Felipe and McCombie's] arguments share a common structure which is to manipulate the value added identity, add some auxiliary assumptions, and then show-under these maintained assumptions - that the data will appear to have been generated by a production relationship of a certain type, typically, but not always, Cobb-Douglas, even when no such relationship exists. (Emphasis added.)

Here is their main claim stated explicitly: "Can a researcher using value data ever establish whether or not the coefficients reflect a production function, or are they simply predetermined by the value added identity? Our answer is that unequivocally the results are always determined by the identity." Yet, the very next sentence in their paper assumes that the weighted average of growth of factor prices and factor shares are all constant. These assumptions are needed to show how the identity leads to estimates that appear to support a Cobb-Douglas production function. Since these assumptions will not always be met, it is clear that the value added identity does not always lead to a spurious Cobb-Douglas result (Temple 2010, 687-688, emphasis added).

Temple's argument, consequently, is that we assert (correctly in our opinion) that the results are "always determined by the identity," even when these assumptions are not meet. But

\footnotetext{
${ }^{4}$ The argument also holds for gross output by adding intermediate materials.
} 
Temple disputes this and argues that if a good proxy for total factor productivity (TFP) can be found,

there is no reason why a researcher should not discriminate between, say, a translog and a Cobb-Douglas specification. Say that the data have been generated by a stable production relationship, and the researcher specifies this relationship correctly, including controls for productivity differences for such as TFP. In that case, the researcher is estimating a model that corresponds to the data generating process. There is no reason for the estimates to be biased, or for the parameters to be unidentified. In contrast, and for the same reason - the equivalence between the form of the estimated model and the generating process - the dynamic version of the value added identity cannot do better than this. It will certainly do worse, when the auxiliary assumptions introduced by Felipe and McCombie are not a good approximation to the data. (Temple 2010, 688, omitting a footnote)

Temple's circular reasoning is readily apparent here. He assumes that a "stable production function exists" [i.e., the data is generated by an aggregate production function]. This can be estimated provided TFP can be correctly specified, another concept dependent on the aggregate production function. ${ }^{5}$ Of course, if one adopts this petitio principii then, of course, the problem is merely one of determining the best specification and estimation techniques, which has been the subject of numerous articles that have estimated the production function. As the "dynamic value added identity" is an identity, then a better way of putting it is that the estimated aggregate production function can do no better than this, rather than vice versa, as Temple argues in the quotation cited above. And if factor shares vary, then, of course, the functional form that gives the best fit to the identity will not be the Cobb-Douglas. But this ignores (rather than refutes) the critique that what is driving the results is the identity, as the estimates are not of a behavioural equation. We spelled this out immediately prior to our argument cited above. As Temple ignores it, it is worth repeating it again.

Equations (1) to (5) in Felipe and McCombie (2006, 669-671) show the formal equivalence between the identity in growth rate form and the general form of the (putative)

\footnotetext{
${ }^{5}$ The growth of total factor productivity is given by $T \hat{F}_{t} \equiv \hat{V}_{t}-\alpha_{t} \hat{L}_{t}-\beta_{t} \hat{J}_{t}$. Making all the usual neoclassical assumptions that an aggregate production function exists with constant returns to scale and factor markets are perfectly competitive with factors being paid their aggregate marginal products, it follows that $T \hat{F} P_{t} \equiv \hat{V}_{t}-a_{t} \hat{L}_{t}-\left(1-a_{t}\right) \hat{J}_{t}$ and from the neoclassical 'dual' to the neoclassical aggregate production, $T \hat{F} P_{t} \equiv a_{t} \hat{w}_{t}-\left(1-a_{t}\right) \hat{r}_{t}$. We are back to the identity, as discussed in the text below.
} 
aggregate production function when the usual neoclassical assumptions are made. No ad hoc, auxiliary, or maintained assumptions are made, pace Temple. To reiterate: write any putative aggregate production function $V=f(L, J, t)$ in growth rate form. This gives:

$$
\hat{V}_{t}=\lambda_{t}+\alpha_{t} \hat{L}_{t}+\beta_{t} \hat{J}_{t}
$$

where $\lambda$ is the rate of technical progress and $\alpha$ and $\beta$ are the output elasticities.

Compare equation (1) with the accounting identity expressed in growth rate form, viz.,

$$
\hat{V}_{t} \equiv a_{t} \hat{w}_{t}+\left(1-a_{t}\right) \hat{r}_{t}+a_{t} \hat{L}_{t}+\left(1-a_{t}\right) \hat{J}_{t}
$$

If the neoclassical economist assumes constant returns to scale, perfect competition, and that the marginal productivity theory of factor pricing holds, then equations (1) and (2) are formally equivalent. But as the latter equation is an identity, it is true irrespective of these assumptions and, indeed, it holds even when the aggregate production function does not exist. (Note that from the identity $T \hat{F} P_{t} \equiv \lambda_{t} \equiv a_{t} \hat{w}_{t}+\left(1-a_{t}\right) \hat{r}_{t}$. See footnote 5.)

Consequently, the argument follows through whether or not factor shares and the weighted growth of the wage rate and the rate of profit are constant. In practice, researchers will attempt to find an explicit functional form that will give a good fit to the data generated by equation (1). Thus we have:

$$
V_{t} \equiv w_{t} L_{t}+r_{t} J_{t} \Rightarrow \hat{V} \equiv a_{t} \hat{w}_{t}+\left(1-a_{t}\right) \hat{r}_{t}+a_{t} \hat{L}_{t}+\left(1-a_{t}\right) \hat{J}_{t} \Rightarrow \hat{V}_{t} \equiv \lambda_{t}+\alpha_{t} \hat{L}_{t}+\beta_{t} \hat{J}_{t} \Rightarrow V_{t}=f\left(L_{t}, J_{t}, t\right)
$$

with the arrows showing the direction of causation. This implies that $a_{t} \equiv \alpha_{t}$ and $\left(1-a_{t}\right) \equiv \beta_{t} \equiv(1-$ $\alpha_{t}$ ). As we have noted, economists try to find a specific mathematical functional form that will closely fit the data generated by equation (1) and, hence, the underlying identity, equation (2). If, and only if, the weighted average of the growth rates of the wage and profit rates are a constant, and factor shares are also constant, will a conventional Cobb-Douglas relationship fit this criterion. If they are not constant, then a more flexible functional form that contains the CobbDouglas as a special case, such as a Box-Cox transformation or the translog, will be required. But these mathematical isomorphisms should not be regarded as aggregate production functions. Consequently, the argument does not apply solely to the case where the aforementioned assumptions hold. As this has been quite generally emphasised throughout the literature on the 
subject, and especially in Felipe and McCombie (2010a), it is surprising that Temple should think otherwise.

The argument is consequently a matter of methodology and logic. What we show are the conditions under which a given form of the production function, say the Cobb-Douglas, would yield good results in terms of the usual statistical diagnostics. This is very different from claiming that specific assumptions or some structure must be imposed for the critique to hold. In fact, an implication of the accounting critique is that unless factor shares and $a_{t} \hat{w}_{t}+\left(1-a_{t}\right) \hat{r}_{t}$ are approximately constant, the estimation of the equation $V=A_{o} e^{\lambda t} L_{t}^{\alpha} J_{t}^{\beta}$ using time-series data will most likely yield poor results. That is to say, implausible estimates of the factor elasticities that are very different from the values of the factor shares and may even be negative. The identity shows that a better fit can be obtained by both a more flexible functional form and time trend. But if these stylized facts hold, then the goodness of fit will potentially be unity and the estimated elasticities must equal the factor shares.

Given this, why has the Cobb-Douglas proved so durable, and why does it so often give a good statistical fit to the data? If we integrate equation (2), we obtain $V \equiv a^{-a}(1-a)^{(1-a)} w^{a} r^{(1-a)} L^{a} J^{(1-a)}$. This is not an approximation, but an isomorphism: it holds exactly for any particular year, whether it is for, say, the UK economy or an individual firm. ${ }^{6}$ As it is a stylized fact (not an assumption) that factor shares do not change greatly between firms in the same industry, and wages and profits show little variation compared to $L$ and $J$, estimating cross-section production functions gives a good fit with a surprisingly high $\mathrm{R}^{2}$ of over 0.9 , and the estimated output elasticities equal the factor shares (Douglas 1976). Time-series data often yield worse results, not because factor shares change dramatically over time (they do not), but because $a \ln w_{t}+(1-a) \ln r_{t}$ is often not well approximated by a linear time trend, or $a \hat{w}_{t}+(1-a) \hat{r}_{t}$ by a constant, as they are subject to cyclical fluctuations.

\footnotetext{
${ }^{6}$ Alternatively, consider the accounting identity and take a particular point on it, say $V^{\prime}, J^{\prime}$ and $L^{\prime}$. Expand both the Cobb-Douglas and the accounting identity in the neighborhood of these points using a Taylor-series expansion (i.e., the hypothetical Cobb-Douglas is at the point of the tangency to the accounting identity at this point). The resulting two equations are formally equivalent. Consequently, as we know the accounting identity must exist, it is this that causes the Cobb-Douglas specification and not the other way around. This was essentially the method and insight of Simon and Levy (1963).
} 
Temple also discusses the distinction between the Solow residual and TFP growth. To interpret the Solow residual as a measure of TFP growth requires equality between factor prices and marginal products. What we show is that the data will always show this, provided one uses the right functional form. This section of Temple's argument also borders on the petitio principii. As is well-known, Solow (1957) came to the "startling" result (Solow 1988, 313) that the growth of factor inputs for the US explained less than one-eighth of the growth of labor productivity, while the rate of technical progress (which is how Solow loosely interpreted the residual) explained the remaining seven-eighths. Far from being startling, a back-of-the-envelope calculation with the identity shows that this result is inevitable. The growth of total factor productivity is defined as $T \hat{F} P \equiv a \hat{w}+(1-a) \hat{r}$. The neoclassical assumptions are existence of an aggregate production function and that factor shares are equal to the aggregate output elasticities. If factor shares are roughly constant (with a labor share of about 0.75 ) and the rate of profit does not vary systematically over time, by using value data the growth of TFP will equate to 75 percent of the rate of growth of productivity. ${ }^{7}$ In fact, Solow found the proportion slightly larger than this, because the rate of profit declined over the period under consideration.

Temple agrees that the growth accounting approach requires the existence of a wellbehaved production relationship, but argues that a more general approach would be needed when there is no longer equality between marginal products and factor products. As examples, he cites the work of Basu, Fernald, and Kimball (2006), Fernald and Neiman (2010), and Temple and Wößmann (2006). It is difficult to see any relevance of these articles to the present debate because all commence by explicitly assuming an aggregate production function exists and use value data. Fernald and Neiman (2010) actually specify a Cobb-Douglas production function!

\section{The Mankiw, Romer, and Weil (1992) Growth Model is Merely a Misspecified Identity} Further evidence of Temple's (2010) misunderstanding on this point is given by the following:

\footnotetext{
${ }^{7}$ Note that growth of labor productivity is given by $\hat{V}-\hat{L} \equiv a \hat{w}+(1-a) \hat{r}+(1-a)(\hat{J}-\hat{L}) \equiv T \hat{F} P+(1-a)(\hat{J}-\hat{L})$. The growth accounting approach normally calculates TFP growth over several years, and given that factor shares are not constant, uses the average value of the shares (based on the Tornqvist approximation to the Divisia index).
} 
As in Simon and Levy (1963) and Simon (1979) they [Felipe and McCombie] examine the cross-section implications of the identity and show that it could lead to a (spurious) production relationship. The argument requires factor shares to be constant and the levels of factor prices to be similar across units. Felipe and McCombie relate this to international data [the Mankiw-Romer-Weil model, 1992] even though the assumption that factor prices are similar across countries is highly implausible. This does not strike Felipe and McCombie as a problem: "the critique does not rest on this assumption and so nothing depends upon whether or not it is correct. If the actual data do not have this property, then researchers who estimate the Cobb Douglas form... will not obtain a very good statistical fit." But their argument has veered off course. In these more general and plausible circumstances, a researcher no longer finds that Cobb-Douglas is a good fit. Instead the researcher concludes appropriately that a Cobb-Douglas technology does not provide a good explanation of the data in question. So what is the problem here? The proposed "tyranny" of the accounting identity seems part-time at best. (Temple 2010, 689-690)

The quotation above shows that Temple misunderstands our arguments concerning the Mankiw et al., (1992) paper. Let us restate Mankiw et al.'s procedure. They posit a "world" aggregate production function that is a Cobb-Douglas. They see no problems in, say, aggregating Indian agriculture with the plough and oxen, the highly mechanized agricultural sector of the US and Europe, the aerospace industry of Europe and the US, the retailing sector with the hypermarkets in the developed countries, and the bazaars of the less developed countries. They therefore assume that the "world elasticity of substitution" is a meaningful concept and that all countries have access to the same level of technology. Commonsense (and a cursory acquaintance with aggregation theory) would suggest that this is not a sensible approach.

But nevertheless, Mankiw et al., find that estimating their specification gives, in these circumstances, a reasonably good statistical fit in terms of the $\mathrm{R}^{2}$, and the coefficients are statistically significant. As they use a (neoclassical) Cobb-Douglas production function and assume initially that growth is at its steady-state rate, they implicitly assume a constant capitaloutput ratio. Later in the paper they introduce a specification purporting to capture the non steady-state growth behavior of the countries.

The question is why do the data give such a reasonably good fit? Is it that the data has not refuted their assumptions underlying the concept of world production function? The answer is no. The reason is that Mankiw et al. use value data and cannot escape the fact that the series of value added, employment, and capital are related through the accounting identity. Looking at their data set, it is apparent that factor shares are roughly constant. This is an empirical 
observation or one of Kaldor's stylized facts, not a "maintained hypothesis" as Temple asserts. In Solow's $(1970,2)$ words, "the ratio of capital to output shows no systematic trend."

What we show is that the initial relatively poor fit of the Mankiw-Romer-Weil model is not because the capital-output or factor shares show considerable variation, but because the wage rate varies considerably between countries. Mankiw et al., assume a constant level of technology, $A_{t}$, where, from the identity, we know that $A_{t} \equiv B w_{t}{ }^{a} r_{t}^{(1-a)}$. We are fully aware that the "assumption that factor prices are similar across countries is highly implausible" as Temple (2010, 689) notes, implicitly criticizing us. Indeed, we discuss this at length in both our critique of Mankiw et al. (1992) (see Felipe and McCombie 2005) and in Felipe and McCombie (2010a, 677). As the accounting identity holds separately for each country (both advanced and less developed nations), then we know immediately that the specification of the model of Mankiw et al., with a constant level of technology, will not lead to a particularly good statistical fit. This indeed proves to be the case. As we point out (Felipe and McCombie 2010a, 676), the identity shows that the assumption of both a constant technology and a spatially invariant rate of technical progress (i.e., $a \ln w+(1-a) \ln r$ and $a \ln \hat{w}+(1-a) \hat{r}$ respectively) by Mankiw et al. will produce a less than perfect statistical fit. If the capital-output ratio did show considerable variation, then the identity shows that Mankiw et al.'s specification is likely to give a poor fit to the data, not that we can suddenly be confident that we can find a specification where the data is actually estimating a "true" production function.

Mankiw et al., (1992) improve the fit by including a human capital variable derived from school enrollment rates. As this is likely to be correlated with the wage rate, it acts as a proxy for the latter in the identity. Once the variation in factor prices is allowed for by regional dummies or is explicitly included in the regression, the Cobb-Douglas gives a good fit without, in the latter case, the need to include human capital, which Mankiw et al. are forced to resort to (Felipe and McCombie 2005). Moreover, the estimated neoclassical speed of convergence becomes infinite. But our argument does not impose a priori the assumptions that factor shares are constant, or of a constant capital-output ratio. We know from the data, given these stylized facts hold, that the accounting identity tells us the Mankiw et al. model is bound to give a good statistical fit to the data (subject to the variability of the real wage rate) before a single regression is run. Felipe and McCombie (2005) confirm this by regression analysis. It is difficult to see any rationale for 
Temple's non sequitur that at this point our discussion "veers off course" (Temple 2010, 690). Empirically, if factor shares did vary considerably and we found another functional form that provides a better approximation to the identity than the Cobb-Douglas, it does not mean, as we have repeatedly emphasised, that we can now be confident that we are estimating an aggregate production function.

The concluding sentences of the above quotation of Temple $(2010,690)$ demonstrate a fundamental confusion and it is worth repeating them:

In these more general and plausible circumstances, a researcher no longer finds that Cobb-Douglas is a good fit. Instead the researcher concludes appropriately that a Cobb-Douglas technology does not provide a good explanation of the data in question. So what is the problem here? The proposed "tyranny" of the accounting identity seems part-time at least (emphasis added).

This implies Temple considers that if the data provide a good fit to the Cobb-Douglas, the researcher can conclude that a Cobb-Douglas technology does provide a good explanation. The "problem here" is that the whole point of the critique is that the existence of the accounting identity shows that no such inference can be made. The corollary is that if, for example, factor shares vary, we cannot suddenly be confident that an aggregate production function, pace Temple, is being estimated. ${ }^{8}$

Temple continues with this line of circular reasoning when he maintains that a constant capital-output ratio

makes little sense in the context of the Solow model. The Solow model can be seen precisely as a theory of adjustment to an equilibrium capital-output ratio. It makes little sense to reject estimates of the model on the basis of a highly restrictive assumption, even less so when that assumption rules out the central mechanism of the model. (Temple 2010, 690)

\footnotetext{
${ }^{8}$ Temple (2010, p.687) argues that "if the data have been generated by a translog, a simpler model such as the CobbDouglas will be an imperfect fit. This is because the output elasticities and factor shares will not be constant over time or across production units. Even if the researcher lacks information on factor shares, standard methods can be used to detect and investigate parameter heterogeneity that has been left unmodelled. The only way Felipe and McCombie can get around these arguments is to rule them out, by assuming that production relationships never exist, and factor shares behave in particular ways." The point to notice is that Temple again assumes that an aggregate production function exists in the form of a translog, which entirely begs the question under discussion. If the shares do show variability then, of course, the Cobb-Douglas relationship (not "production function") will give an imperfect fit, and a more flexible functional form (not "production function") is needed.
} 
This is again a case of the petitio principii fallacy because, as we have noted, the correct measure in Solow's growth model is the physical capital-output ratio. Of course, because of the heterogeneity of physical output and capital goods, there is no such thing as an aggregate physical capital-output ratio. See also Simon (1986, 172-183, Appendix A, “A Constant LongRun $K / Y$ Ratio is a Meaningless Observation”) for a discussion of why the constant-price monetary value of the capital-output ratio will always tend to be approximately constant regardless of what is happening to the various individual physical capital-output ratios. If the data cannot show whether or not the aggregate production function exists, then the same applies to the whole Solow growth model, upon which it depends. It is not a case of rejecting the estimates of the parameters of the model - we know exactly what the estimates of the model are; they are the factor shares, but they cannot be interpret as the physical aggregate output elasticities. Again, Temple misunderstands the argument.

To summarize: all Felipe and McCombie (2005) does is to show using the identity, the circumstances under which the augmented Solow model - the specification that Mankiw et al. (1992) estimated - will lead to good results. We do not claim that the assumptions about the constancy of the wage and profit rates, the factor shares, and the capital-output ratio are correct theoretically or empirically (although some of them, as we have argued, are stylized facts in the literature). What we argue is that Mankiw et al.'s (1992) regression will work if and only if these conditions are met. In fact, what we implied in our discussion about the identity was that their poor initial results derived from the fact that all these stylized facts about the data were not met (especially the constancy of the level and growth of "TFP"). If these assumptions about the data are not correct, then the equation Mankiw et al. (1992) estimated will give a poor statistical fit. This is exactly what originally happened, and our point was that this can be seen without the need for estimating any regression to explain why. ${ }^{9}$ The identity also tells us how to improve the goodness of fit.

\footnotetext{
${ }^{9}$ It is difficult to understand the implications of Temple's $(2010$, fn. 7, 691) remark noting the fact that the model of Mankiw et al., can be expressed as a function of the logarithm of the aggregate labour share. He comments "But that quantity has been assumed constant across countries, so their [Felipe and McCombie's] suggested reinterpretation seems internally inconsistent (Temple 2010, fn 7, 691). This result was actually proved by Felipe and McCombie $(2005,375)$ and discussed there. Felipe and McCombie prove that if the stylized facts mentioned in their paper hold, then the model of Mankiw et al. reduces to the logarithm of the aggregate labor factor share. But note that this does
} 


\section{There Is No Econometric Solution to the Implications of the Critique}

As we are dealing with a misspecified representation of an accounting identity, the solution is not to use instrumental variables, or any other econometric technique - as used by, for example, Olley and Pakes (1996), Blundell and Bond (2000), and Levinsohn and Petrin (2003). On this, see Felipe et al. (2008). Temple cites Ackerberg et al. (2006) as an example of progress towards solving this identification problem, but again they assume the existence of an aggregate production function. The poor statistical results are not due to standard econometric problems (the identity does not have an error term). Poor statistical fits using time-series data are often found even though factor shares are relatively constant. The problem, as noted earlier, is that $a_{t} \widehat{w}_{t}+\left(1-a_{t}\right) \hat{r}_{t}$ is not constant, but has a pronounced cyclical component. Consequently, its approximation by the constant term in the regression in growth rates (or a linear time trend when log-levels are used) is responsible for the poor results. In these circumstances, it is necessary to find the correct approximation to this equation (e.g., through a different type of time-trend such as a trigonometric function). ${ }^{10}$ If factor shares vary greatly, then the Cobb-Douglas form will also give a poor statistical fit. In this case, a more flexible functional form for the identity is required.

\section{The Problem Cannot Be Solved by Disaggregating the Value Measures of Capital (and}

Output) Disaggregation of labor and capital services as in Jorgenson and Griliches (1967) does not solve the problem. Temple argues that with sufficient disaggregation, the aggregate production function may (or presumably may not) exist, and all that remains is a statistical problem of correctly specifying its functional form. This is also incorrect. As we clearly stated in Felipe and McCombie (2010a, 673-674), disaggregating the relationship between output, labor, and capital as $V_{i}=f_{i}\left(J_{1 i \ldots . . .} J_{n i}, L_{1 i} \ldots L_{n i}\right)$ does not solve the problem. ${ }^{11}$ The production function

not have to be constant across countries. This theoretical result arises from the fact that the accounting identity is replicating the model of Mankiw et al., which assumes identical output elasticities (and, hence, from the identity, identical factor shares). The same result arises for each country if we start from the case where the elasticities and, hence the shares, differ between the individual countries, although this will reduce the goodness of fit of the crosscountry regressions. It is difficult to see how this is any way internally inconsistent. (The only interpretation we can make is that Temple is implicitly assuming that if factor shares differ for some unspecified reason, the regressions are estimating a "true" aggregate production function.)

${ }^{10}$ Adjusting the inputs, especially capital, for differences in capacity utilisation will also have the same effect.

11 Temple's argument is puzzling, as he accepts that our arguments are not about input mis-measurement, but about the dangers of using value added to measure output, and constant price value data to measure the capital stock. 
can only be estimated if the disaggregation is such that physical quantities are used. The problem is not that the inputs are badly measured in value terms, but that they have to be measured in value terms in the first place.

The question is not so much about disaggregation, but the type of data, value versus physical. As we have argued, although not exempt from problems, with data in physical terms it is possible to estimate the technical parameters. Temple argues that "if the inputs have been disaggregated appropriately, then a production function may well exist, and the only remaining problem is a purely statistical one: can the data be used to establish the form of the relationship?" (Temple 2010, 687). Temple argues that, provided we sufficiently disaggregate the constant price value data of the capital stock and employment, the resulting aggregate production function exists and therefore can be estimated using value data. ${ }^{12} \mathrm{He}$ does have the proviso that the correct measure total factor productivity is required, which he sees as a difficult, but not insuperable problem. This legerdemain occurs in his 2006 paper and he repeats it in his 2010 comment. Thus, he seems to consider that the critique rests on a "fundamental identification problem" (Temple 2010, 685). However, we have long argued that, pace Temple, it is not a statistical identification problem if this implies that it is possible, in principle, to specify a model where the aggregate production function can be statistically refuted. Temple $(2010,687)$ paradoxically also recognizes that "the argument is not simply one about statistical identification."

To reiterate our 2006 argument: the problem is that, to be meaningful, production functions must be estimated using physical quantities. As these are heterogeneous and have to be summed, constant price value data have to be used. Consequently, no matter how many inputs (and outputs) are specified and measured in value terms, the problem posed by the identity still arises. Jorgensen and Grilichres (1967, 253)—see Felipe and McCombie (2006)—start out by assuming the existence of an aggregate production function, perfect competition, and that factors are paid their marginal products. They use this approach to disaggregate the constant price value

\footnotetext{
${ }^{12}$ Temple only concentrates on the disaggregation of inputs, although his argument must logically apply to the different outputs, which means that we have to disaggregate the aggregate production function.

${ }^{13}$ However, from a careful reading of the text, it is not clear if he merely correctly attributes this to us, or whether he accepts that it logically follows from our critique.
} 
indices of the capital stock in order to try empirically to eliminate the residual. Jorgensen and Grilichres (1967, footnote 2) explicitly state that because of their assumptions, their approach cannot be used to test the marginal productivity theory of factor pricing.

\section{Simulation Results Confirm the Importance of the Critique.}

Temple does not seem to appreciate the full implications of Felipe and McCombie's (2006) simulations. Although he indicates the "simulations results do have genuine interest" (Temple 2010, 690), he believes that our findings depend on some auxiliary assumptions. But what assumptions do we make that drive the results? As part of our (2010a) reply to Temple, we cite a study of ours ion which we show that with a constant mark-up pricing, the data will give a perfect fit to a Cobb-Douglas production function, where the estimated coefficients of the log of capital and labor are 0.75 and 0.25 , respectively; while the true output elasticities were 0.25 and 0.75, respectively. We assume the existence of well-defined micro-production functions not because we necessarily believe they exist, but to show the implications of the critique even under these circumstances.

Temple argues that as the estimated coefficients of the log of capital and labor differ markedly from the true output elasticities, there must be large differences between the rewards to factors and their marginal products. "Those are not the usual assumptions made in interpreting the results from estimated production functions" (Temple 2010,690). But any researcher with only access to the value data and interpreting the results of the estimated "production function" would find that the estimated "output elasticities" equal the factor shares. Thus, the neoclassical researcher would erroneously conclude that markets are perfectively competitive, constant returns to scale prevail, and that factors are paid their marginal products. This would also be the case, as we show in our simulations, when the true production function displays increasing returns, or, indeed, there is no well-defined relationship between the outputs and inputs. In the model we use, prices are determined by a mark-up on unit costs, which in turn is determined by, for example, the state of competition in the industry and the relative power of labor and capital in the wage bargaining process. It may well differ from the physical marginal productivity of labor 
if the firm (but not the researcher) knows the true micro-production function, but so what? ${ }^{14}$ Firms, under neoclassical assumptions, will set the rewards equal to the marginal product measured in value terms, and are unlikely to know a worker's physical marginal product. (Moreover, there are vast sectors of the economy where there is no reliable independent measure of output even in constant price value terms.)

There have been a number of other important simulation studies that demonstrate how the data will give a good fit to a Cobb-Douglas, even though we know by the construction of the hypothetical data that this is not reflected in the underlying technology. These include a study in which the micro-production functions deliberately violate the conditions for successful aggregation (Fisher 1971), where the production function has a fixed-coefficients technology (Shaikh 2005), and where firms satisfice, rather than optimize (Nelson and Winter 1982). For a discussion of these studies, see Felipe and McCombie (2010b).

\section{CONCLUSIONS}

To conclude, despite some acknowledged points of agreement, Temple does not appreciate the full implications of the critique. The fact that very simple functional forms and two highly aggregate variables (with the constant price value of the capital stock, in particular, subject to all kinds of statistical measurement errors) can often explain over 90 percent of the variation in output is due simply to the fact that the three variables are definitionally related. This explanation does not depend upon any specific assumptions, such as constant factor shares, constant level, or growth, or the weighted average of the growth rate of the wage rate and profit rate, or a constant capital-output ratio. Allowing these to vary does not mean that all the aggregation problems and the problems posed by the accounting identity disappear and that we can be confident of estimating a technological relationship.

\footnotetext{
${ }^{14}$ Temple argues that some argue that "no firm knows its production function," but he considers it knows its costs and that well-behaved cost functions are mirrored by the existence of production functions. But a cost function is also derived from the accounting identity and will be mirrored by a "spurious" production function. (See Felipe and McCombie 2011-12). A neoclassical cost function does not guarantee the existence of a well-behaved production function.
} 
The key disagreement between Temple and us is that we argue that using value data, a researcher can always find a perfect fit to the data, with the estimated coefficients equal to the factor shares (and not only when these are constant), even though no aggregate production function exists. Temple does not share this conclusion. We have shown that the only reason why factor shares and the output elasticities may differ is that the specific functional form estimated does not accurately track the accounting identity. Temple unwittingly concedes our case when he states: "Moreover, the production function may appear simple and well-behaved even when no stable relationship exists and the true extent of the misspecification may never be detected" (Temple 2010, 689; emphasis added). This accurately summarizes our position, although we argue it is not a case of "may," but of "will;" and furthermore, that the statement "no stable relationship" includes the case when plausibly the aggregate production function does not exist. An implication of the above quotation is that the researcher can never know whether or not the estimates of the aggregate production function mean anything. As we noted above, Temple correctly states, "the argument is not simply one of statistical identification" (Temple 2010, 687), but then inconsistently and erroneously states that "to the extent that a researcher can control for the variation in TFP and takes care over the specification, the simultaneous existence of the value added identity does not invalidate these methods." Unfortunately for the researcher, it does, and Temple has not demonstrated otherwise. 


\section{REFERENCES}

Ackerberg, D. A., J. K. Caves, and G. Frazer. 2006. "Structural Identification of Production Functions. Oslo, Norway: University of Oslo. http://folk.uio.no/rnymoen/Ackerberg_Caves_Frazer.pdf

Basu, S., J.G. Fernald, and M.S. Kimball. 2006. “Are Technology Improvements Contractionary?” American Economic Review 96(5): 1418-48.

Blundell, R. and S. Bond. 2000. "GMM Estimation with Persistent Panel Data: An Application to Production Functions." Econometric Reviews 19(3): 321-40.

Douglas, P. H. 1976. "The Cobb-Douglas Production Function Once Again: Its History, Its Testing, and Some New Empirical Values.” Journal of Political Economy 84(5): 903-915.

Felipe, J. and J. S. L. McCombie. 2005. "Why Are Some Countries Richer Than Others? A Skeptical View of Mankiw-Romer-Weil's Test of the Neoclassical Growth Model." Metroeconomica 56(3): 360-392.

- 2006. "The Tyranny of the Identity: Growth Accounting Revisited." International Review of Applied Economics 20(3): 283-299.

_ 2007. "On the Rental Price of Capital and the Profit Rate: The Perils and Pitfalls of Total Factor Productivity Growth." Review of Political Economy 19(3): 317-345.

— 2010a. "What is Wrong with Aggregate Production Functions. On Temple's Aggregate Production Functions and Growth Economics." International Review of Applied Economics 24(6): 665-684.

- 2010b. "On Accounting Identities, Simulation Experiments and Aggregate Production Functions: A Cautionary Tale for (Neoclassical) Growth Theorists." In M Setterfield (ed.), Handbook of Alternative Theories of Economic Growth,189-207. Cheltenham, UK: Edward Elgar.

- 2011-12. "On Herbert Simon's Criticisms of the Cobb-Douglas and CES Production Functions." Journal of Post Keynesian Economics 34(2): 275-293.

Felipe, J., R. Hasan, and J. S. L. McCombie. 2008. "Correcting for Biases When Estimating Production Functions: An Illusion of the Laws of Algebra?" Cambridge Journal of Economics 32(3): 441-459.

Fernald, J. G. and B. Neiman. 2010. "Growth Accounting with Misallocation: Or Doing Less with More in Singapore." NBER Working Paper No. 16043. Cambridge, MA: National Bureau of Economic Research.

Fisher, F. M, 1971. "Aggregate Production Functions and the Explanation of Wages: A Simulation Experiment." Review of Economics and Statistics 53(4): 305-25. 
—. 2005. "Aggregate Production Functions: A Pervasive, But Unpersuasive, Fairytale." Eastern Economic Journal 31(3): 489-491.

Jorgenson D. W. and Z. Griliches. 1967. “The Explanation of Productivity Change.” Review of Economic Studies 34(99): 249-283.

Levinsohn, J. and A. Petrin. 2003. "Estimating Production Functions Using Inputs to Control for Unobservables." Review of Economic Studies 70(2): 317-341.

Mankiw, N. G., D. Romer, and D. N. Weil. 1992. "A Contribution to the Empirics of Economic Growth.” Quarterly Journal of Economics 107(2): 407-437.

Nelson R.R. and S.G. Winter. 1982. An Evolutionary Theory of Economic Change. Cambridge MA: Harvard University Press.

Olley, S. and A. Pakes. 1996. "The Dynamics of Productivity in the Telecommunications Equipment Industry.” Econometrica 64(6): 1263-1298.

Shaikh, A. 2005. "Nonlinear Dynamics and Pseudo-Production Functions." Metroeconomica 31(3): 447-466.

Simon, H. A. and F. K. Levy, 1963. "A Note on the Cobb-Douglas Function.” Review of Economic Studies 30(2): 93-4.

Simon, H. A. 1979. “On Parsimonious Explanations of Production Relations.” Scandinavian Journal of Economics 8(4): 459-474.

Simon, J. L. 1986. Theory of Population and Economic Growth. Oxford: Basil Blackwell.

Solow, Robert M. 1957. "Technical Change and the Aggregate Production Function." Review of Economics and Statistics 39(3): 312-320.

- 1970. Growth Theory: An Exposition, $2^{\text {nd }}$ ed. Oxford: Oxford University Press.

—. 1988. "Growth Theory and After." American Economic Review 78 (3): 307-317.

Temple, J. R.W. 2005. "Dual Economy Models: A Primer for Growth Economists.” Manchester School 73(4): 435-478.

- 2006. "Aggregate Production Functions and Growth Economics." International Review of Applied Economics 20(3): 301-317.

- 2010. "Aggregate Production Functions, Growth Economics, and the Part-Time Tyranny of the Identity: A reply to Felipe and McCombie." International Review of Applied Economics 24(6): 685-692.

Temple, J. R.W and L Wößmann. 2006. "Dualism and Cross-Country Growth Regressions." Journal of Economic Growth 11(3): 187-228. 